\title{
Investigating environmental management practices within the Northern Cape wine supply chain
}

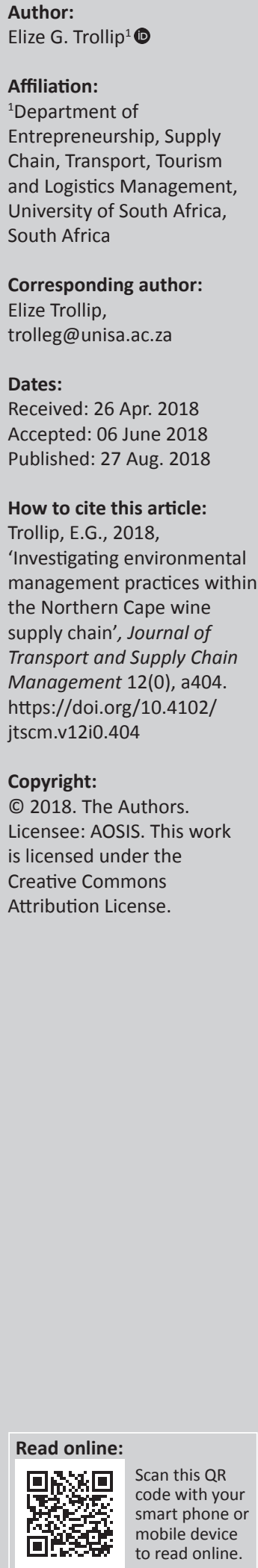

Background: Environmental management systems and practices have become a necessity in wine supply chains, given their vulnerability to climate change. Climate change could lead to a 55\% loss of wine-cultivating land in South Africa by 2050, which would harm the first two tiers of the wine supply chain.

Objectives: The objective was to investigate the current environmental systems and practices applied in the first two tiers of the Northern Cape wine supply chain.

Method: This qualitative exploratory study was conducted by semi-structured interviews to determine the various environmental management systems and practices adopted by role players. The data collected were analysed by thematic analysis.

Results: The results indicated the implementation of an environmental management tool, namely the Integrated Production of Wine scheme. Supportive practices such as water- and energy-wise approaches, soil management and waste management were also identified. Furthermore, a sincere relationship between farmers, cellars and viticulturists results in collaboration based on mutual information sharing and cooperation between role players to reduce their environmental impact.

Conclusion: The various environmental management practices and the collaborative approach between role players can serve as an example to other agricultural supply chains.

\section{Introduction}

Globally, it has become vital for organisations to adopt environmental management practices owing to pressure from stakeholders to mitigate climate change (Monczka et al. 2016:609). Consequently, there is a growing interest in environmental management systems (EMSs) and environmentally considerate organisational performance. Moreover, organisations are requested to address environmental issues such as energy, fresh water, pollution, transportation, waste management and climate change.

Environmental management systems are vital if organisations are to compete internationally. Suppliers with the most environmentally sustainable measures are often preferred when contracts are awarded (Monczka et al. 2016:107). Therefore, manufacturers such as wine producers (wine cellars) who supply to retailers need to consider the impact of their operational practices on the environment. Furthermore, organisations should have a broader focus than merely their own operations. Wine cellars should also take an interest in their suppliers' (farmers') efforts towards environmental protection.

All role players in the wine industry ought to integrate environmental awareness and environmental sustainability plans in the various stages of the supply chain (Grant, Trautrims \& Wong 2015:27). Role players in this chain are farmers, wine cellars, logistics service providers, warehouses, retailers and final consumers, all of whom contribute to greenhouse gases in their daily operations. Consequently, these role players must consider factors such as soil erosion and depletion, energy usage and a lack of recycling to prevent deterioration of the environment on which they are dependent (Rainey \& Araujo 2015:110). These components of the supply chain will not be viable without a sustainable environment. A paper entitled 'Climate change, wine and conservation' shows that by 2050 South Africa will lose $55 \%$ of its wine-cultivating land. This will impact directly on the wine farmer, who is the first tier of the wine supply chain (Hannah et al. 2013:6909). In 2015, Rainey and Araujo (2015:114) warned that the agricultural industry, of which the wine industry is an integral part, is the most vulnerable to climate change. In 2017 the Western Cape lost 25\% of its vineyards as a result of drought (Gosling 2018). 
The South African wine industry, the context of this study, comprises seven geographical units, of which the Northern Cape is one. The Northern Cape is known for its high temperatures and low rainfall (Northern Cape Wines 2014). From the farmer's perspective, warmer temperatures impact directly on the growth of vines and the wine-growing regions themselves (Palliotti et al. 2014:45). However, the environmental perspective maintains that the higher temperatures and warmer environments of the Northern Cape lead to a higher usage of energy in the wine-processing phase, especially in the cooling down of wine. In addition, the wine cellars of the Northern Cape are located considerable distances from their South African markets, necessitating long-distance transportation, thereby increasing their environmental impact (Trollip 2016). If these cellars export, longer distances are covered to reach harbours. Energy and transport are the major greenhouse gas contributors in the wine supply chain (Winemag 2014).

Research on this geographical unit is limited because most research articles on the wine industry address the Western Cape geographical unit. They focus on individual topics at specific wineries in the Western Cape (Åslund 2013; Lubkoll, Brend \& Gauché 2011; NCC 2015; van der Merwe, van Dyk \& van Vuuren 2011). On top of that, these studies have dealt with one environmental issue at a time and have neglected others such as energy, fresh water, air pollution, waste management, transportation and climate change. Furthermore, after the perusal of databases such as SABINET and Google Scholar, no research could be found that treats all the major environmental management issues in one study, and no study focused on the Northern Cape wine supply chain.

\section{Problem statement and research objective}

Environmental management systems and practices have become a necessity in wine supply chains given their vulnerability to climate change. Energy and transportation are environmental obstacles in the Northern Cape wine supply chain. Little is known about initiatives regarding environmental management systems and practices. This study aims to address this gap in the literature and identify the unique methods and practices applied by the first two tiers in this supply chain to reduce their impact on the environment.

The objective is, therefore, to investigate and report on environmental management practices used in the Northern Cape wine supply chain.

\section{Contribution}

This article contributes to knowledge about rural areas such as the Northern Cape, where little research has been conducted. Research on the various environmental practices applied by the first tier in the Northern Cape wine supply chain and the role of collaboration in guiding supply chain sustainability provides valuable insights for practitioners and academics.

\section{Literature review}

\section{Environmental management}

Long-term sustainability is a vital goal of any supply chain (Bowersox et al. 2013:402). One of the objectives of sustainability is to protect the environment (Antweiler 2014:18). Environmental management relates to the management of human interactions with the natural environment. It entails processes, procedures and methods to ensure that measures are in place to minimise adverse effects on environmental resources (Antweiler 2014:1). Organisations should adopt an EMS to address environmental issues (Johnsen, Howard \& Miemczyk 2014:354-355). An example of an EMS is the International Organisation for Standardisation: Environmental Management System (ISO 14001), which is a requirement from suppliers (Monczka et al. 2016:258).

ISO 14001 is a certification process that ensures the credibility of the organisation's environmental protection activities (Johnsen et al. 2014:355). Certain South African wine cellars experience pressure from international retailers regarding their environmental impact (Back 2010). Organisations need an in-depth understanding of environmental issues to manage them and to respond appropriately to challenges, problems, government regulations and stakeholder pressure (Antweiler 2014:32-52). The primary environmental issues are energy supply, fresh water supply, air pollution, waste management, transportation and climate change (Antweiler 2014:32-52).

\section{Environmental issues}

Globally, energy supply depends on exhaustible fossil fuels, which produce harmful emissions. Alternatives are natural renewable sources (solar and wind energy) with far lower emissions than fossil fuels. However, they cannot be stored and are available only during sunny and windy conditions. Electricity is the greatest contributor to South Africa's carbon footprint as Eskom generates electricity mainly via coal-fired power stations (CCC 2010).

Industries require fresh water to manufacture products. In the agricultural industry farmers use water in cultivation (irrigation) and processing and manufacturing (Grant et al. 2015:213). South Africa is the 30th driest nation on Earth and will face a water shortage as from 2025 (Crowley 2015). Currently, the Western Cape is experiencing a severe water shortage (Gosling 2018). Both the quality and quantity of water are critical factors in the wine industry (Trollip 2016).

Furthermore, manufacturing generates high percentages of pollution. Wine production involves pumps, compressors and refrigeration, which cause high levels of air and noise pollution (Silverman, Marshall \& Cordano 2005:153). Waste management processes aim to reduce waste and to reuse and recycle products (Grant et al. 2015:115). In South Africa, wine cellars contribute to solid waste in the form of the skins and stems of grapes (Trollip 2016). 
Transport is a significant contributor to climate change and greenhouse gas emissions (Greenhouse Gas Protocol 2012). Organisations are dependent on transport. A primary concern is air pollution resulting from the exhaust gases released by petrol- or diesel-powered vehicles and devices. Wine in South Africa is mostly transported by road, causing major gas emissions (Winemag 2014).

Climate change is currently the most serious environmental concern. Environmental abuse and greenhouse gases lead to climate change. Increases in greenhouse gases result in extreme weather phenomena such as floods, wildfires, heat waves, hailstorms and droughts. Droughts are among the major impacts of climate change in the agricultural sector (Ziervogel et al. 2014:6909). The wine industry has been identified as one of the greatest greenhouse gas contributors in South Africa and has been directly linked to climate change (CCC 2014).

Other major environmental issues in wine supply chains are the inputs (water, energy, chemical) and outputs (production waste, greenhouse gases, air pollution) of a process (Pullman \& Sauter 2012:9). It is evident that proper environmental practices must be implemented when considering the environmental issues in wine supply chains.

Thus, environmental perspectives in wine supply chains should include conservation, usage reduction and good business management practices. Conservation deals with the responsibility of minimising an organisation's dependence on energy, water and other natural resources. Usage reduction includes activities that reduce waste and greenhouse gases, as well as recycling. Good business management practices involve collaboration with supply-chain role players and the recycling of packaging materials to increase environmental sustainability (Bowersox et al. 2013:403-404).

\section{Environmental management tools}

The literature identified EMS, ISO 14001 and the Integrated Production of Wine (IPW) scheme as methods to manage environmental sustainability. In South Africa, IPW certification confirms that environmental protection procedures were considered in growing grapes and producing wine. Unfortunately, IPW is voluntary (WOSA 2010).

\section{Research methodology}

This was an exploratory study that employed a qualitative exploratory research design. This design provides rich data and new insights in a topic on which limited information is available (Quilan et al. 2015:125).

\section{Sampling}

Five Northern Cape wards were sampled. Snowball sampling was used to identify some of the participants. There were 15 participants including three winemakers, five wine cellar representatives, five farmers (who supply grapes to the cellars) and two viticulturists (Cooper \& Schindler 2014:152).

\section{Procedure}

Interview questions were developed from the exploratory literature review (Hofstee 2006:115) and translated into Afrikaans because most participants were Afrikaansspeaking. A pilot study was conducted to verify the suitability of the questions and ensure the credibility of the data collected (Saunders, Lewis \& Thornhill 2012:451). After the pilot, no changes were made to the questions. Before the interviews, participants were informed about the purpose of the study. The semi-structured interviews were conducted at the premises of the participants and lasted $43 \mathrm{~min}$ on average. The interviews aimed to identify key environmental methods and practices applied to protect the environment. Interviews were audio-recorded with the permission of all participants. A professional data transcriber transcribed the interviews and the transcripts were checked by the researcher to ensure that the data were accurate.

\section{Analysis}

Thematic analysis was used to analyse the data. Quilan et al. (2015:336) define thematic analysis as 'the analysis of data through the use of themes and codes'. Third-party experts, the researchers themselves or computer programs can do thematic data analysis (Quilan et al. 2015:320-321). A qualitative-data analyst compiled themes and codes from the data, resulting in categories and subcategories, and the researcher used the research question and objectives to verify the themes and codes.

\section{Trustworthiness}

As stated above, interview questions were compiled from the literature (Smyth 2006:7). Data collection methods, namely interviews and field notes, were triangulated to ensure the credibility, validity and dependability of the research. To ensure authenticity, the researcher supported inferential statements in the data with direct verbatim quotes from the interviews (Tobin \& Begley 2004:292). Interview reports (results) were shown to participants, thereby increasing their credibility and validity. The dependability, confirmability and transferability of this study were supported by a paper trail that included recordings, transcribed data and documentation of the study (Green \& Thorogood 2014:120).

\section{Findings and argument}

Four themes are identified in Table 1, namely the nature of the industry, conservation, usage reduction and good management practices. The themes are supported by categories and codes and are then elaborated upon with pertinent extracts from the interview data.

\section{Theme 1: The nature of the industry}

Regulations and standards exist by which farmers and cellars should abide (Lancaster \& Ras 2012:20). The following quotes confirm compliance with the standards:

'We have to comply with certain standards.' (Participant 5, male, cellar representative) 
TABLE 1: Summary of themes, categories and codes.

\begin{tabular}{|c|c|c|}
\hline Theme & Category & Subcategory \\
\hline \multirow[t]{6}{*}{ The nature of the industry } & Well regulated & The Integrated Production of Wine Scheme \\
\hline & & The Wine and Agricultural Ethical Training Association \\
\hline & & ISO 14000 (Environment Management System) \\
\hline & & ISO 22000 (Food Safety Management) \\
\hline & & The British Retail Consortium \\
\hline & & Food Safety System Certification \\
\hline & Energy: energy-wise approaches & Solar energy, less energy-intensive machinery \\
\hline & Soil: soil management approaches & Impact studies, $\mathrm{X}$ cultivar (a new cultivar) \\
\hline \multirow[t]{2}{*}{ Usage reduction } & Waste management & Recycling water: use of wineskins and stems \\
\hline & Greenhouse gas (carbon footprint) reductions & Transportation: centralised bottling and packaging (PET and carton packaging) \\
\hline $\begin{array}{l}\text { Progressive supply chain management practices } \\
\text { (good business management practices) }\end{array}$ & Good supplier relationships and collaboration & Experts: PET facility on premises \\
\hline
\end{tabular}

Source: Adapted from Trollip, E.G., 2016, 'Environmental management practices in the Northern Cape wine supply chains', Unpublished MCom dissertation, University of South Africa, Pretoria. ISO, International Organisation for Standardisation; PET, polyethylene terephthalate.

'There are labour laws, IPW, WIETA [Wine and Agricultural Ethical Training Association], food safety standards ...' (Participant 12 , male, farmer)

Standards such as ISO 22000 (Food Safety Management) for food safety bring a sense of order, a guarantee regarding the quality of a product. The preceding finding indicates that the wine industry has a high regard for the industry's regulations and standards.

\section{Well regulated}

The aspect of high regulation refers to the IPW and the International Organisation for Standardisation: Environmental Management System (ISO 14000) standards.

The Integrated Production of Wine scheme: The interview participants (farmers and cellar representatives) confirmed that the IPW provides them with guidelines on the protection of the environment, including record keeping of all substances and chemicals that are used. The participants indicated that they are IPW compliant, which is one of the requirements of buyers. The following direct quotes highlight the guidance of IPW and the participants' IPW compliance:

'IPW forms the framework or guidelines in which producers operate the practice, the chemicals, our working methods, the way you handle the chemicals and the product, etc.' (Participant 7, male, cellar representative)

'I can proudly say that with every audit, we have been certified.' (Participant 3, male, cellar representative)

'Bulk wine buyers look for that accreditation, IPW. Farmers do what they have to. Every third year they have to do their IPW course to know what is expected of them when it comes to fertilising and poisoning.' (Participant 10, male, cellar representative)

'It is the training of each producer and winemaker and also the training of the cellar interior.' (Participant 5, cellar representative)

'Retailer X, Z, U and all wine places - they want those specifications, and if you do not comply with those, then they do not take the wine.' (Participant 3, male, cellar representative)

From this data it is evident that the wine industry is regulated. It is also clear that suppliers require proof of environmental protection from the cellars. These findings correspond with the literature on buyers' demands for environmental protection considerations (Monczka et al. 2016:793-794). Furthermore, the findings show that farmers and cellars (the first two tiers of the Northern Cape wine supply chain) comply with environmental protection standards and, to some extent, are committed to environmental conservation. Through the training provided by IPW, the environmental awareness is carried out through the first tier of the Northern Cape wine supply chain.

\section{International Organisation for Standardisation:} Environmental Management System (ISO 14000 series of standards): A question was asked about ISO 14000 environmental standards and whether they applied any of the standards or were certified. None of the participants used any of the ISO 14000 environmental standards, mainly because they were not involved in exporting to the UK. The next quote confirms the requirement for exporting to certain countries:

'We do not have one [ISO 14000 certification].' (Participant 15, male, cellar representative)

'For table grapes and dried grapes, they will. They are very strict with ISO. Especially if you want to export to the UK.' (Participant 3 , male, cellar representative)

The finding corresponds to the statements made by Monczka et al. (2016:609) and Back (2010) that ISO 14000 certification is required by international organisations. IPW certification will not be sufficient if the cellars in the Northern Cape wine supply chain wish to expand their market to include the UK. They will need to improve their environmental management practices to get their ISO 14000 certification.

\section{Theme 2: Conservation}

Organisations need to find ways to reduce their dependence on natural resources to achieve sustainability. Furthermore, the wine supply chain needs a sustainable environment because of its reliance on the cultivation of grapes in a natural environment (Chopra \& Meindl 2016:504). The agricultural industry is dependent on a sustainable environment, which includes fertile soil, water and energy. 


\section{Soil: Soil management approaches}

Fertile soil is vital for the cultivation of grapes, and as a result it is impossible for farmers to reduce their dependence on fertile soil. Moreover, the five farmers and viticulturist who participated in the study believed that one needs to take care of what one has and explained their efforts to reduce their impact on the environment. The following quotes provide examples of methods applied to protect the environment:

'Approval for planting is given only after an impact study has been done. We are involved in plant improvement, and the focus is on the soil and adapting to soil types. It is no use establishing a crop and after some time you realise that it does not agree with the soil.' (Participant 9, male, farmer)

'We have also started to plant new cultivars. The X cultivar is doing quite well in this low-frost area. It is immune to illness and we do not need to spray it with anything. We just put it in the ground, fertilise it. Therefore, the vineyard soil in the long term takes care of itself. You just have to water and prune it. Some cover crops create a mat that competes with weeds, so you do not have to spray.' (Participant 13, male, viticulturist)

It is important to note the choice of low-maintenance cultivars (e.g. X cultivar) that thrive in the harsh weather conditions of the Northern Cape. Fewer pesticides and fertilisers will have a reduced impact on land, air and water because there are fewer threats of contamination. In addition, the use of cover crops and earthworms to reduce weeds in vineyards and to improve the fertility of the soil points toward efforts to be sustainable. These findings agree with the literature, which indicates that farmland should be protected for present and future generations (Rainey \& Araujo 2015:124). The participants' commitment to protecting the environment through various methods that improve environmental performance and sustainability is in line with Chopra and Meindl's (2016:504) recommendation that role players in a supply chain should find methods to achieve long-term sustainability. The farmers show a positive culture of reverence, adherence and passion for the preservation of the Earth and the environment, which are essential steps towards environmental management practices.

\section{Water: Water management approaches}

All the participants agreed that their water consumption needs were probably the highest in the country because of the exceedingly hot climate of the Northern Cape. A major concern was the quality and quantity of the water, which creates additional challenges. The following quotes highlight various water management approaches used by the participants:

'The other thing is to return the water to nature as clean as possible, to keep the water clean so that you can use it for agricultural activities. The water is circulated; we have someone who is with the firm that treats our water.' (Participant 14, male, wine maker)

'We are the only group in the wine industry that has a permit from the Department of Water for evaporation dams. Water we use to clean the cellar flows straight into the evaporation dam. The only impact we have on the environment is the evaporation dam itself and the evaporation of the water.' (Participant 3, male, cellar representative)

'Thanks to cover crops, you do not have to water that often. It reduces your water usage because it keeps the soil moist.' (Participant 12, male, farmer)

'I think our water quality and quantity are of great concern at this stage. I have doubts about its sustainability in the future; one worries about it.' (Participant 6, male, farmer)

From these findings it is evident that farmers are concerned about the quality and quantity of water, which correlates with Rainey and Araujo's (2015:126-128) concerns regarding water quality and quantity. The efforts of the participants to save and clean the water are in line with literature that suggests that water management strategies should include the recycling, reuse and filtering of water (Antweiler 2014:37). Evaporation dams were not identified in the literature as a water management approach. They can assist in the protection of soil and prevent wastewater, which might contain chemicals that contaminate soil.

\section{Energy: Energy-wise approaches}

It is clear from the following quotes that farmers and cellar representatives make use of energy-wise approaches to reduce their greenhouse gases and carbon footprint:

'I use solar power.' (Participant 8, male, farmer)

'Our first solar energy provision will be in operation at the factories. We have to use as little electricity as possible to cool the wine; we now know that electricity's carbon footprint is not the smallest, especially in our country.' (Participant 15, male, cellar representative)

'We try to stick to the latest technology. The motors that will be installed will all be low-energy motors; it is all about saving energy.' (Participant 3, male, cellar representative)

Electricity has a huge carbon footprint and the findings demonstrate the participants' environmental awareness and commitment to saving energy by implementing new technologies such as solar energy. It is also evident that the participants focused on environmental management to reduce their carbon footprint. In addition, these approaches used by the participants correspond with Antweiler's (2014:2) view that a focus on environmental management can lead to innovations.

\section{Theme 3: Usage reduction}

From a supply chain perspective, waste management can address usage reduction and recycling initiatives, which in turn can decrease greenhouse gas emissions (carbon footprint) and prevent climate change (Bowersox, et al. 2013:404).

\section{Waste management: Recycling initiatives}

The cellar representatives pointed out that they adhered to waste management through the recycling and reuse of water. 
The following quotes highlight the waste management efforts by the participants:

'We re-circulate water continuously. We do not necessarily use fresh water every day, but as soon as a slimy layer forms in the tanks, we replace the water and clean the tanks.' (Participant 4 , female, wine maker)

'The peels and stems are used to make compost so that they are put back into the vineyard.' (Participant 9, male, farmer)

One way of overcoming the scarcity of water is to use water sparingly and to recycle. Another example of recycling is the use of skins and stems as compost and ground cover in the vineyards. These findings are in line with Grant et al.'s (2015:155) recommendations that waste management and recycling initiatives should start on site or at the source of origin.

\section{Greenhouse gas (carbon footprint) reductions}

The increase in greenhouse gases (which account for climate change) leads to a rise in temperatures, new rainfall patterns, droughts and floods (Rainey \& Araujo 2015:130-131). Organisations need to find ways to reduce their greenhouse gases. The major greenhouse gas contributors in South Africa are electricity and transportation (EDF 2014). The participants agreed that the major contributors to the carbon footprint (greenhouse gases) were electricity and transportation. Electricity and energy has already been addressed by energywise approaches under the conservation theme. Because the Northern Cape wine region is fairly remote, all dry goods need to be purchased from Cape Town or Johannesburg. Greenhouse gases (carbon footprint) refer to transportation, centralised bottling and polyethylene terephthalate (PET), which can be both a help and hindrance in wine farmers' attempts to shrink their carbon footprint.

Transportation and air pollution: Transportation is a problem because the target area is situated quite far from urban and business areas and transport hubs. The following quotes highlight the efforts made by the participants to reduce their greenhouse gases:

'We have our transportation organisation. Tankers and all trucks bought in the past two years, all came in with clean emission gases.' (Participant 3, male, cellar representative)

'We use a specific truck brand, because of its low fuel consumption per kilometre.' (Participant 10, male, cellar representative)

'We recycle wine from our $X$, which previously we would not have been able to do. Your $\mathrm{X}$ is worth little because if we transport it to the Cape, and with transport costs being so high, you get nothing for it. Therefore, we now recycle some wines, and the transport component might decrease. Like I said, you should halve your carbon footprint by the things you implement.' (Participant 15, male, cellar representative)

Newer transport modules that use new technologies can assist in the reduction of pollution and costs. These findings agree with the literature, which indicates that organisations should use environmentally friendly trucks that generate less pollution (Grant et al. 2015:60).

\section{Centralised bottling and packaging}

Bottling and packaging are among the major contributors to greenhouse gases in a wine supply chain (CCC 2012). The participants mentioned that their bottling process was centralised. They use a centralised method to enhance their efforts in environmental protection and to lower their costs. The following quote highlights the advantage of a centrally managed bottling facility:

'We have a location disadvantage. We are far from everything. Bulk wine is moved with a tanker, to XX and then it is centrally blended and bottled. This is the lowest impact we can have on the environment, and it reduces our costs.' (Participant 11, male, wine maker)

The use of centralised bottling operations lowers transportation costs and the impact on the environment by minimising the transportation of dry goods to various cellars. These findings correlate with Wisner, Tan and Leong (2016:62), who indicate that lower transportation costs are among the benefits of centralisation. Furthermore, because less transportation is needed to obtain dry goods, the carbon footprint and greenhouse gas emissions are reduced in the Northern Cape wine supply chain.

Polyethylene terephthalate: The participants pointed out that they had a PET bottle facility on their premises. The main cellar doing the bottling supplied the building and the premises, while X Plastics produced the PET bottles on their premises. Thanks to these centralised facilities the participants saved on transport and thus improved their environmental performance. The following quote elaborates how this decision reduced greenhouse gases:

'We now have a PET-blowing facility on our premises. No more shipments of empty bottles that are completely ineffective because of the distance.' (Participant 15, male, cellar representative)

One way to stay competitive and improve an organisation's environmental performance is to find innovative methods. A PET facility at the centralised bottling premises allows the organisations to save on transportation and to reduce their greenhouse gas emissions and carbon footprint. The literature indicates that PET bottles are cheaper than glass bottles because it takes fewer carbon emissions to produce a PET bottle and, besides, it is recyclable (Grant et al. 2015:122).

Carton packaging: All the cellar representatives indicated that they used carton packaging to export their wines. The following quote highlights the use of carton packaging:

'We focus on box packaging because of our carbon footprint and it is obviously cost-effective.' (Participant 14, male, wine maker)

From the quotes it is evident that the motivation for the use of carton packaging was its lower carbon footprint and its cost-effectiveness. These findings correspond with those of Grant et al. (2015:122), who state that through appropriate packaging, such as carton packaging, an organisation can reduce greenhouse gases. Carton packaging is usually made from recycled material and can enhance an organisation's 
waste management initiative. In addition, carton packaging is robust; it does not break easily and is lightweight. This also reduces transportation costs. All the reductions discussed above show that, through effective supply chain management and the implementation of environmental practices, resources can be available at the right time and that cost reductions, innovative technologies and a reduction of greenhouse gases are possible.

\section{Theme 4: Progressive supply chain management practices (good business management practices)}

According to Wisner et al. (2016:4), organisations can operate more successfully if they are closely involved with their suppliers and customers. It is vital for any organisation to have long-term relationships and to work together with the main or strategic suppliers because this contributes to innovation (Wisner et al. 2016:78-79).

\section{Good supplier relationship and collaboration}

A key to supply chain management is the formation of collaborative relationships with suppliers in a supply chain (Bowersox et al. 2013:344). Good supplier relationships and cross-tier collaboration refer to communication with experts and with the local PET facility.

Experts: Another interesting aspect that emerged was information supplied by expert consultants. Experts provide knowledge and assistance that help role players to reduce their environmental impact. The following quotes give an indication of the important role experts' play:

'I think things have improved since the viticulturist joined hands with the winemakers, the cellar and our producers. The farmer has become more willing to assist. We confer with each other and decide which grapes, especially our premium A1 grapes, we want to take in at the right sugar level. Also to ensure that the processes run correctly, that the vineyard and the farmer work well together in order to deliver the right product.' (Participant 14, male, wine maker)

'We have the benefit of a viticulturist at every cellar who gives guidance about spraying programmes and planting. You have to plant if the cellars have a need.' (Participant 1 , male, farmer)

'We are currently doing some experiments and we look at the type of plant that will decrease the use of chemicals, fertiliser and so on between the rows of vines. We do this continuously to ensure a good quality grape through effective agricultural practices. We try to decrease the use of chemicals and, let me tell you, these people no longer spray the dreadful stuff.' (Participant 13 , male, viticulturist)

Polyethylene terephthalate facility on the premises: PET has been discussed in the section about the reduction of greenhouse gases. In addition, the use of PET bottles is another way to establish a good relationship with a supplier. The main cellar, which does the bottling, supplies the building and the premises and X Plastics produces the PET bottles on the premises. The next quotes describes how costeffective this is:
'We now have a PET-blowing facility on our premises. There are no more shipments of empty bottles that are completely ineffective because of the distance.' (Participant 15, male, cellar representative)

'We make our premises available to $\mathrm{X}$ Plastics. The building is our property. They do the work for us on the premises. It is a big savings.' (Participant 14, male, wine maker)

'The focus is always on rands and cents at the end of the day, but environmental conservation makes your product more costeffective down the line.' (Participant3, male, cellar representative)

These findings are indicative of a culture of cooperation between farmers, cellars, X Plastics and experts (viticulturists) as well as of information sharing. Furthermore, these findings correspond with the literature, which claims that cooperation and exchange of information are necessary for an effective supply chain (De Villiers, Nieman \& Niemann 2017:7). Moreover, for an organisation to operate successfully, it needs to become more involved with its suppliers (Wisner et al. 2016:4). An excellent way to reduce the impact on the environment is to work together and to share information.

\section{Management of environmental impact and practical implications}

The objective of the study was to identify the methods applied by farmers and cellars to ensure the sustainability and long-term survival of the Northern Cape wine industry. Figure 1 summarises the practices implemented by these first two tiers of the supply chain.

The literature indicates that organisations should be aware of environmental issues to reduce their impact on the environment. The results of this study confirm that the participants were indeed aware of environmental issues and could apply a variety of methods, practices or techniques, as depicted in Figure 1, to reduce their environmental impact.

Regarding the issue of energy, the participants claimed that energy had a major impact on their organisation and supply chain. To reduce their dependence on energy, the

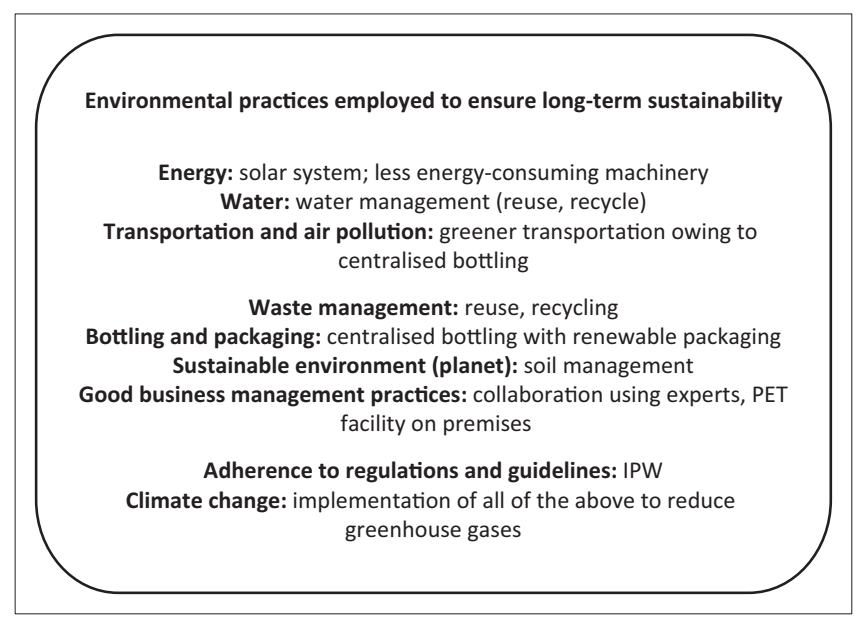

Source: Trollip, E.G., 2016, 'Environmental management practices in the Northern Cape wine supply chains', Unpublished MCom dissertation, University of South Africa, Pretoria.

FIGURE 1: Summary of environmental practices applied by the participants. 
participants implemented energy-wise approaches, such as solar energy. Furthermore, they made use of the latest technology and low-energy motors in their cellars to save energy. Concerning water management, the water used in cooling systems was recycled and cellars had a water treatment plan in place for reusing water. Moreover, the participants used low-maintenance vine cultivars that required little water. Air pollution and transportation were additional environmental problems, and the participants explained that they bought a green brand of trucks that used less fuel and reduced gas emissions. As to waste management, the participants indicated that they reused and recycled skins and stems. Farmers collected the skins and stems from various cellars and reused them as compost in their vineyards. Furthermore, the cellars made use of renewable carton packaging as well as new types of packaging to reduce their carbon footprint in the bottling process. These new types of packaging included PET bottles and renewable carton packaging. Furthermore, a centralised bottling facility was in operation, with a PET bottling facility at the wine cellar, which further reduced their carbon footprint and transportation and other costs.

The farmers (the first tier) realised the importance of ensuring that the soil is sustainable in the long-term. They mentioned soil management practices such as the use of natural products in vineyards, skins and stems for fertilising and planting low-maintenance cultivars that are resistant to fairly high temperatures. Furthermore, experts were consulted regarding the planning and implementation of new technologies to protect the environment. Collaboration and information sharing occurs between the first two tiers of role players in the Northern Cape wine supply chain to improve their environmental performance. A strong culture of cooperation and cost management is evident, such as the PET bottling facility at the wine cellar premises and the on-site production of PET bottles by X Plastic.

Although the literature stresses the importance of an EMS such as ISO 14000 certification, the role players did not apply any of the ISO environmental standards. However, they adhered to the regulations and guidelines set out by IPW, which can be viewed as their EMS. Moreover, the training provided by IPW brought about greater environmental awareness within the Northern Cape wine supply chain. All the participants agreed that climate change was a reality and, consequently, the motivation behind their efforts to reduce their impact on the environment.

\section{Ethical considerations}

An ethical clearance certificate was obtained from the Research Ethics Committee at the researcher's university. Informed consent was obtained from the participants. These consent forms stipulated the research objectives and emphasised the fact that participation was voluntary and that participants could withdraw at any time. Confidentiality forms were signed to ensure confidentiality.

\section{Conclusion}

The main objective of this study was to identify the environmental management practices implemented by the first two tiers of role players in the Northern Cape wine supply chain. The literature study indicated that the major environmental issues are energy, fresh water, waste management, air pollution, transportation and climate change. Energy and transportation contribute in a significant way to greenhouse gases in a wine supply chain. This study investigated the environmental management practices adopted by the first two tiers of the Northern Cape wine supply chain. The environmental management practices implemented by farmers (first tier) and cellars (second tier) to reduce their impact on the environment and ensure sustainability are water conservation, waste and soil management and the use of cleaner energy and transportation, which lead to the reduction of air pollution. The practice of environmental management is achieved by adhering to the guidelines and training provided by the IPW. Information sharing and collaboration between these role players in the Northern Cape wine supply chain is seen as an important factor in environmental awareness and a move towards long-term sustainability. The results revealed a strong commitment from all the participants to the protection of the environment for future generations.

However, the recommendation is made that they apply for ISO 14000 certification to expand their market to include the UK. Moreover, it is suggested that a comprehensive study be conducted of all role players in the supply chain to determine how the Northern Cape wine supply chain can implement measures that will enable it to be classified as a sustainable environment supply chain. In addition, an empirical study could be conducted that includes the differences between the Western Cape and Northern Cape wine industries with a focus on environmental management practices.

\section{Acknowledgements}

The author would like to acknowledge the reviewers of the draft manuscript.

\section{Competing interests}

The author declares that she has no financial or personal relationships that may have inappropriately influenced her in writing this article.

\section{References}

Antweiler, W., 2014, Elements of environmental management, University of Toronto Press, Toronto.

Åslund, I., 2013, 'Opportunities for improved environmental sustainability of a wine producer in South Africa - Natural resource management and climate change adaptation and mitigation', Master's thesis in Soil Science, Swedish University of Agricultural Sciences.

Back, S., 2010, South Africa: Eco-labels may contravene WTO Rules, viewed 28 Apri 2010, from http://allaafrica.com/stories/printable/201004060096.html

Bowersox, D.J., Closs, D.J., Cooper, M.B. \& Bowersox, J.C., 2013, Supply chain logistics management, 4th edn., McGraw-Hill, Singapore.

CCC, 2010, Confronting climate change. A South African fruit and wine initiative. The South African fruit and wine industry carbon calculator, The Protocol, Version 1 01 February 2010, viewed 04 February 2015, from http://awsassets.wwf.org.za/ downloads/sa_fruit_wine_protocol.pdf 
CCC, 2012, Confronting climate change. A South African fruit and wine initiative Strategic framework reference document, Version 1. 02 January 2012, viewed 04 February 2015, from http://www.wineteck.co.za/docs2012/Strategic-FrameworkFebruary 2015, from http://www.wineteck.co.za/
Reference-Document-Version1-2-Jan-2012.pdf

CCC, 2014, Confronting climate change. A South African fruit and wine initiative. Industry level trends report. Year 2: 2013 Carbon footprint results for the CCC South African fruit and wine sample group, viewed 04 February 2015, from http:// climatefruitandwine.co.za/Documents/CCC Industry\%20Level $\% 20$ Trends $\% 20$ Report_2013.pdf

Chopra, S. \& Meindl, P., 2016, Supply chain management: Strategy, planning and operation, 6th edn., Pearson, Harlow.

Cooper, D.R. \& Schindler, P.S., 2014, Business research methods, 12th edn., McGrawHill, Singapore.

Crowley, K., 2015, 'South Africa braces for water shortages', Sunday Times, 20 May, viewed 20 May 2015, from http://www.timeslive.co.za/sundaytimes/stnews/ 2015/05/20/South-Africa-braces-for-water-shortages

De Villiers, G., Nieman, G. \& Niemann, W., 2017, 'Introduction to supply chain management', in G. De Villiers, G. Nieman \& W. Niemann (eds.), Strategic logistics management: A supply chain management approach, 2 edn., pp. 1-18, Van management: A supply chain
Schaik Publishers, Pretoria.

Environmental Defense Fund. South Africa (EDF), 2014, The world's carbons markets: A case study guide to emissions trading, viewed 07 February 2015, from http:// www.ieta.org/assets/EDFCaseStudyMarch2014/south\%20africa\% $\%$ case $\% 20$ study\%20march\%202014.pdf

Gosling, M., 2018, Cape farmers lose $25 \%$ of orchards, vineyards as result of drought - Expert, viewed 22 March 2018, from https:www.news24.com/SouthAfrica/ News/cape-farmers-lose-25-of-orhards-vineyards-as-result-of-droughtexpets-20180322

Grant, D.B., Trautrims, A. \& Wong, C.Y., 2015, Sustainable logistics and supply chain management. principles and practices for sustainable operations and management, rev. edn., Kogan Page Limited, London.

Green, J. \& Thorogood, N., 2014, Qualitative methods for health research, 3rd edn., Sage, London.

Greenhouse Gas Protocol, 2012, Greenhouse gas protocol, viewed 05 September 2014, from http://www.ghgprotocol.org/

Hannah, L.R., Patrick, R., Ikegami, M., Shepard, A.V., Shaw, M.R., Tabor, G. et al., 2013, 'Climate change, wine, and conservation', PNAS (Proceedings of the National Academy of Sciences) 110(17), 6907-6912. https://doi.org/10.1073/pnas.1210127110

Hofstee, E., 2006, Constructing a good dissertation: A practical guide to finishing a Master, MBA, or PhD on schedule, EPE Publications, Sandton.

Johnsen, T.E., Howard, M. \& Miemczyk, J., 2014, Purchasing and supply chain management: A sustainability perspective, Routledge, New York.

Lancaster, C. \& Ras, P.J., 2012, Making both ends meet. On practices of sustainable development governance strategies in the South African-European table grape supply chain, Gildeprint Drukkerijen, Enschede.

Lubkoll, M., Brent, A.C. \& Gauché, P., 2011, A pre-feasibility study of a concentrating solar power system to offset electricity consumption at the Spier Estate, viewed 31 March 2015, from http://www.crses.sun.ac.za/files/services/conferences/annualstudent-symposium-2011/4-18nov_lubkoll.pdf
Monczka, R.M., Handfield, R.B., Giunipero, L.C. \& Patterson, J.L., 2016, Purchasing and supply chain management, 6th edn., Cengage Learning, Boston, MA.

NCC (NCC Environmental Services), 2015, Assessing the damage and restoring the land at Vergelegen Wine Estate, viewed 31 March 2015, from http://www.nccgroup.co.za/case-studies/assessing-damage-and-restoring-lang-vergeleng-wineestate0

Northern Cape Wines, 2014, Estates and Winelands, viewed 03 September 2014, from http://www.sa-venues.com/attractionsnc/wine-estates/default.php

Palliotti, A., Tombesi, S., Silvestroni, O., Lanari, V., Gatti, M. \& Poni, S., 2014, 'Changes in vineyard establishment and canopy management urged by earlier climaterelated grape ripening: A review', Scientia Horticulturae 178, 43-54. https://doi. org/10.1016/j.scienta.2014.07.039

Pullman, M. \& Sauter, M., 2012, Sustainability delivered. Designing socially and environmentally responsible supply chains, Business Expert Press, New York.

Quilan, C., Babin, B., Carr, J.C., Griffin, M. \& Zikmund, W.G., 2015, Business research methods, 1st edn., Cengage Learning, London.

Rainey, D.L. \& Araujo R.J., 2015, The pursuit of sustainability: Creating business value through strategic leadership, holistic perspectives and exceptional performance, Information Age Publishing Inc.

Saunders, M., Lewis, P. \& Thornhill, A., 2012, Research methods for business students, 6 th edn., Pearson Education Limited, London.

Silverman, M., Marshall, S. \& Cordano, M., 2005. 'The greening of the California Wine Industry: Implications for regulators and industry associations', Journal of Wine Research 16(2), 151-169. https://doi.org/10.1080/09571260500331574

Smyth, R., 2006, 'Exploring congruence between Habermasian philosophy, mixedmethod research, and managing data using NVivo', International Journal of Qualitative Methods 5(2), 1-10. https://doi.org/10.1177/160940690600500204

Tobin, G.A. \& Begley, C.M., 2004, 'Methodological rigour within a qualitative framework', Journal of Advanced Nursing 48(4), 388-396. https://doi.org/10.1111/j.13652648.2004.03207.x

Trollip, E.G., 2016, 'Environmental management practices in the Northern Cape wine supply chains', Unpublished MCom dissertation, University of South Africa, Pretoria.

Van der Merwe, A., van Dyk, F.E. \& van Vuuren, J.H., 2011, 'Decision support for grape harvesting at a South African winery', ORION 27(2), 83-100. https://doi org/10.5784/27-2-99

Winemag, 2014, Northern Cape wine region, viewed 13 March 2014, from http:// winemag.co.za/northern-cape-wine-region/

Wisner, J.D., Tan, K. \& Leong, G.K., 2016, Principles of supply chain management: A balanced approach, 4th edn., South-Western Cengage Learning, Boston, MA.

WOSA, 2010, Wines of South Africa: South Africa introduces world's first sustainability seal, viewed, 30 August 2011, from http://www.wosa.co.za/news_wosa_article. php?id=1303

Ziervogel, G., New, M., Van Garderen, E.A., Midgley, G., Taylor, A., Hamann, R. et al., 2014, 'Climate change report impacts and adaptation in South Africa', WIREs Climate Change 5, 605-620. https://doi.org/10.1002/wcc.295 